\title{
OPEN Endogenous levels of cytokinins, indole-3-acetic acid and abscisic acid in in vitro grown potato: A contribution to potato hormonomics
}

\author{
Martin Raspor $\mathbb{1}^{1,6 *}$, Václav Motyka $\mathbb{B}^{2,6}$, Slavica Ninković $\mathbb{D}^{1}$, Petre I. Dobrev $\mathbb{D}^{2}$,

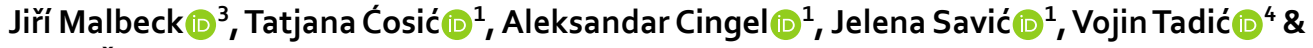 \\ Ivana Č. Dragićević $\mathbb{D}^{5}$
}

A number of scientific reports published to date contain data on endogenous levels of various phytohormones in potato (Solanum tuberosum L.) but a complete cytokinin profile of potato tissues, that would include data on all particular molecular forms of cytokinin, has still been missing. In this work, endogenous levels of all analytically detectable isoprenoid cytokinins, as well as the auxin indole3-acetic acid (IAA), and abscisic acid (ABA) have been determined in shoots and roots of 30 day old in vitro grown potato (cv. Désirée). The results presented here are generally similar to other data reported for in vitro grown potato plants, whereas greenhouse-grown plants typically contain lower levels of $\mathrm{ABA}$, possibly indicating that in vitro grown potato is exposed to chronic stress. Cytokinin $\mathrm{N}$-glucosides, particularly N7-glucosides, are the dominant cytokinin forms in both shoots and roots of potato, whereas nucleobases, as the bioactive forms of cytokinins, comprise a low proportion of cytokinin levels in tissues of potato. Differences in phytohormone composition between shoots and roots of potato suggest specific patterns of transport and/or differences in tissue-specific metabolism of plant hormones. These results represent a contribution to understanding the hormonomics of potato, a crop species of extraordinary economic importance.

Plant hormones, also called phytohormones, are major factors controlling plant growth and development. They are divided into several classes based on chemical structure and biological roles. Major phytohormone classes include cytokinins, auxins, abscisic acid, gibberellins, ethylene, brassinosteroids, jasmonates, salicylic acid and strigolactones ${ }^{1,2}$.

Cytokinins (CKs) are a group of plant hormones with a wide spectrum of biological roles. Natural CKs share the structure of $N^{6}$-substituted adenine, whereby the nature of the $N^{6}$-substituent defines them as either isoprenoid or aromatic ${ }^{3}$. The adenine-like structure of CKs and their biosynthetic dependence on adenine metabolism suggest their close physiological connection to the processes including growth and cell division, in which the actively dividing cells produce large amounts of nucleobases and ribosides, including adenine and adenosine, for de novo synthesis of DNA.

In isoprenoid CKs, the $N^{6}$-atom of adenine is substituted with an isoprenoid $\left(\mathrm{C}_{5}\right)$ chain derived from dimethylallyl diphosphate. This CK class is the most widespread, and consists of $N^{6}-\left(\Delta^{2}\right.$-isopentenyl)adenine (iP),

${ }^{1}$ Department of Plant Physiology, Institute for Biological Research "Siniša Stanković" - National Institute of Republic of Serbia, University of Belgrade, Bulevar Despota Stefana 142, 11060, Belgrade, Serbia. ${ }^{2}$ Laboratory of Hormonal Regulations in Plants, Institute of Experimental Botany of the Czech Academy of Sciences, Rozvojová 263, CZ-165 02, Prague 6, Czech Republic. ${ }^{3}$ Laboratory of Mass Spectrometry, Institute of Experimental Botany of the Czech Academy of Sciences, Rozvojová 263, CZ-165 02, Prague 6, Czech Republic. ${ }^{4}$ Mining and Metallurgy Institute, Zeleni Bulevar 35, 19219, Bor, Serbia. ${ }^{5}$ Department of Plant Physiology, Faculty of Biology, University of Belgrade, Studentski trg 16, 11000, Belgrade, Serbia. ${ }^{6}$ These authors contributed equally: Martin Raspor and Václav Motyka. *email: martin@ibiss.bg.ac.rs 
cis-zeatin (cZ), trans-zeatin ( $t$ Z), dihydrozeatin (DHZ), and their conjugates. Cis- and trans-zeatin isomers are cisand trans- hydroxy derivatives of iP, respectively, whereas DHZ represents a saturated form of zeatin. Structural differences in CK side chains dictate differences in receptor binding - which determines their physiological role, but also in substrate affinity for enzymes involved in their metabolism, further causing differences in their metabolic regulation $^{3-5}$.

Free CK bases (also called CK nucleobases: $c Z, t Z, D H Z$ and iP) can be converted to a number of classes of molecular conjugates (the system of their abbreviations adopted and modified according to Kamínek et al. ${ }^{6}$ ) such as:

- ribosides ( $c Z R, t Z R, D H Z R$ and $i P R)$ - products of ribosylation of the $N^{9}$-atom of the adenine ring of $c Z$, $t Z$, $\mathrm{DHZ}$ and iP, respectively;

- ribonucleotides (CK phosphates)- riboside-5'-monophosphate (RMP), -diphosphate (RDP) or -triphosphate (RTP) derivatives;

- $O$-glucosides and $O$-xylosides - products of glucosylation or xylosylation of the oxygen atom in the side chains of $c Z, t Z, D H Z$ and their respective ribosides ${ }^{5,7}$;

- $\quad N$-glucosides - products of N3-, N7- or N9-glucosylation of the adenine ring of $c Z, t Z, D H Z$ or iP $\mathrm{P}^{5}$.

The structures and molar masses of CK nucleobases, ribosides, $\mathrm{O}$-glucosides, $\mathrm{N7}$ - and $\mathrm{N9}$-glucosides are shown in Fig. 1.

Biological activity of CK conjugates, primarily CK ribosides, has been debated for long, but recent work has proven that within plant membranes, CK receptors are only able to effectively bind CK nucleobases, thus making them the only genuine bioactive forms ${ }^{8}$. Conversions of CK nucleobases into ribosides, nucleotides, $O$-glucosides, $\mathrm{O}$-xylosides and $\mathrm{N3}$-glucosides are reversible processes, whereas $\mathrm{N7}$ - and $\mathrm{N9}$-glucosylations are irreversible ${ }^{5,9}$. Ribosylation and $\mathrm{O}$-glucosylation are believed to play a major role in temporary modification of CKs for purposes of transport and storage, respectively ${ }^{4}$. Ribosides are the main form in which CKs are transported through the plant. The current model proposes that CKs are transported through the xylem mostly in the form of $t \mathrm{ZR}$, which, upon unloading in leaves, undergoes metabolic conversion either into the biologically active $t Z$, or into storage forms by means of $O$-glucosylation ${ }^{4,10,11}$. Conversely, phloem transportation occurs in the form of $\mathrm{PPR}^{4,10}$. On the other hand, $\mathrm{O}$-glucosylation is thought to be the most suitable for purposes of CK storage, as a reversible but chemically stable modification, resistant to catabolic degradation by cytokinin oxidase/dehydrogenase $\mathrm{e}^{4,12}$. N7and N9-glucosides are also stable molecules but N7- and N9-glucosylations are chemically irreversible and do not allow further regeneration of biologically active $\mathrm{CKs}^{3,5}$.

Aromatic CKs, named for the aromatic substitution of the $\mathrm{N}^{6}$-atom of the adenine ring, have only recently been acknowledged as a widespread group of CKs, likely to play important roles in biological processes that might be distinct from those regulated by isoprenoid $\mathrm{CKs}^{13,14}$, but data on their occurence in plant tissues have remained scarce until recently, when their universal presence in plants has been suggested ${ }^{7,14}$.

It is believed that CKs occur in all plants. Isoprenoid CKs represent one of the most abundant phytohormone groups, having been found in almost all plants examined to date, including algae ${ }^{15}$ and bryophytes ${ }^{16}$. In vascular plants, their levels typically amount to $1-100 \mu \mathrm{g} / \mathrm{g}$ fresh weight (FW), being the highest in seeds and storage organs ${ }^{4}$. The most abundant CK of higher plants is $t Z$; it is also believed to have the most important biological role. The iP-type CKs are also highly abundant, mostly in the form of iPR. The importance of $c Z$-type CKs in plant development has been denied for long, but in the last years their involvement has been confirmed in a variety of physiological processes ${ }^{7,17}$.

There is growing research interest for CK physiology in potato (Solanum tuberosum L.) due to numerous evidence for the involvement of CKs in the commercially important process of tuberisation ${ }^{18-23}$. A number of reports containing measurements of phytohormones in various tissues of potato plants grown in various conditions (in vitro, greenhouse) have been published so $\mathrm{far}^{22,24-33}$. Data on amounts of particular molecular forms of isoprenoid CKs, as well as the auxin indole-3-acetic acid (IAA), and abscisic acid (ABA), measured in control plants in these studies, are summarised in Table 1. In addition, a report on endogenous levels of aromatic CKs in both in vitro and greenhouse-grown potato plants was published by Baroja-Fernández et al. ${ }^{34}$.

Comparison between values for endogenous levels of phytohormones in Table 1 is complicated by the use of different measurement units (pmol or ng per $1 \mathrm{~g} \mathrm{FW}$ or dry weight - DW) in different studies. Conversion between $\mathrm{pmol} / \mathrm{gFW}$ and $\mathrm{ng} / \mathrm{gFW}$ can be carried out using molar mass of a given molecule as the conversion factor. On the other hand, it is impossible to make precise conversions between units per $1 \mathrm{~g} \mathrm{FW}$ and DW, but generally, concentrations per $1 \mathrm{~g}$ DW are expected to have up to 10 -fold higher values than corresponding concentrations per $1 \mathrm{~g} \mathrm{FW}$, as DW typically corresponds to 2-9-fold larger values of FW, depending on the water content of plant tissues ${ }^{35}$.

Among the publications listed in Table 1, only few include reports on endogenous levels of certain CK conjugates ${ }^{25}$ or $c Z$-type $\mathrm{CKs}^{32,33}$ in potato. The first report on the whole CK profile of potato shoots and roots (cv. Désirée, grown in vitro) has been published by our research group in 2012, dividing CKs into four groups based on their conjugation status and physiological function, but without breaking them down into individual molecular forms $\mathrm{s}^{22}$.

Recent biotechnological approaches increasingly rely on manipulating the metabolism and signal transduction pathways of plant hormones, making the understanding of hormonomics a necessary step in endeavors to enhance productivity and resistance to stress of economically important plant species ${ }^{36}$. The present work is intended as a contribution to potato hormonomics, attempting to provide the first complete CK profile, including all analytically detectable molecular forms of isoprenoid CKs in both shoots and roots of potato (cv. Désirée) grown in vitro. Additionally, we present the levels of IAA and ABA and compare these data to other reports available in literature. 
<smiles></smiles>

$c Z$

$(M=219.2)$<smiles>C/C(=C/C[C@@H](C)c1nccc2[nH]cnc12)CO</smiles>

$t Z$

( $M=219.2)$<smiles>CC(CO)CCCNc1ncnc2[nH]cnc12</smiles>

$\mathrm{DHZ}$

( $M=221.2$ )<smiles>CC(C)=CCNc1ncnc2[nH]cnc12</smiles>

iP

( $M=203.2$ )

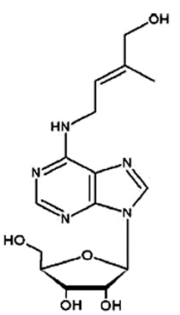

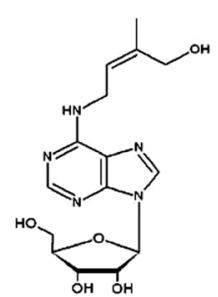<smiles>CC(CO)CC[C@H](C)c1nccc2c1ncn2C1OC(O)C(O)C1O</smiles><smiles>CC(C)=CC[C@H](C)c1nccc2c1ncn2C1OC(O)[C@H](O)[C@@H]1O</smiles>

\section{cZR}

$(M=351.4)$

\section{tZR}

( $M=351.4$ )

iPR

$(M=335.4)$

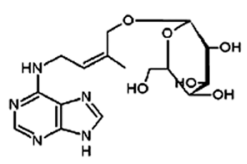

CZOG

( $M=381.4)$

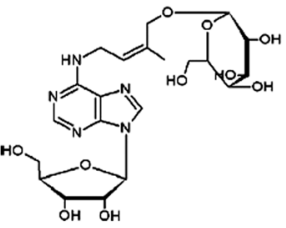

cZROG

$(M=513.5)$

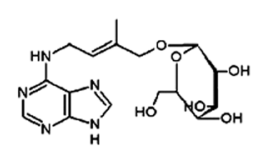

tZOG

$(M=381.4)$

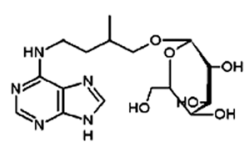

DHZOG

( $M=383.4$ )

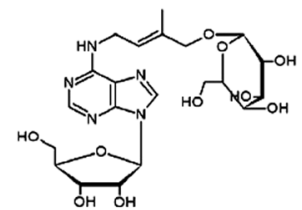

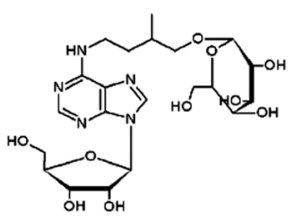

$t$ ZROG

DHZROG

$(M=515.5)$

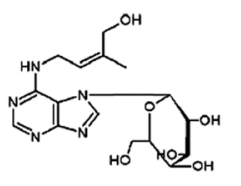<smiles>CC(=CC[C@H](C)c1ncnc2nccnc12)CO</smiles><smiles></smiles>

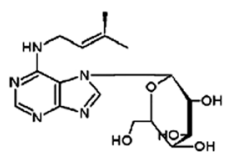

$c Z 7 G$

tZ7G

( $M=381.4)$

$(M=381.4)$

DHZ7G

( $M=383.4$ )

iP7G

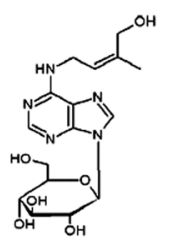

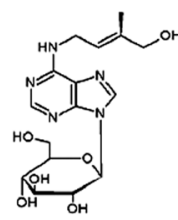

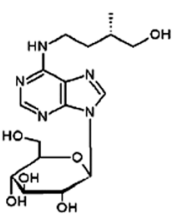

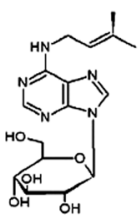

cZ9G

( $M=381.4)$

tZ9G

( $M=381.4$ )

DHZ9G

( $M=383.4$ )

Figure 1. Molecular structure of isoprenoid cytokinins. Molar mass ( $M[\mathrm{~g} / \mathrm{mol}])$ of each cytokinin molecule is given below the corresponding formula. $c \mathrm{Z}$ - cis-zeatin; $t \mathrm{Z}$ - trans-zeatin; $\mathrm{DHZ}$ - dihydrozeatin; iP - $N^{6}$ $\left(\Delta^{2}\right.$-isopentenyl)adenine; $c Z R$ - cis-zeatin 9-riboside; $t Z R$ - trans-zeatin 9-riboside; DHZR - dihydrozeatin 9-riboside; iPR - $N^{6}$ - $\left(\Delta^{2}\right.$-isopentenyl)adenine 9-riboside; $c Z O G$ - cis-zeatin O-glucoside; $t Z O G$ - trans-zeatin $O$-glucoside; DHZOG - dihydrozeatin $O$-glucoside; $c Z R O G$ - cis-zeatin 9-riboside $O$-glucoside; $t$ ZROG trans-zeatin 9-riboside $O$-glucoside; DHZROG - dihydrozeatin 9-riboside $O$-glucoside; $c Z 7 \mathrm{G}$ - cis-zeatin 7-glucoside; $t Z 7 G$ - trans-zeatin 7-glucoside; DHZ7G - dihydrozeatin 7-glucoside; iP7G - $N^{6}-\left(\Delta^{2}\right.$-isopentenyl) adenine 7-glucoside; $c Z 9 G$ - cis-zeatin 9-glucoside; $t Z 9 G$ - trans-zeatin 9-glucoside; DHZ9G - dihydrozeatin 9-glucoside; iP9G - $N^{6}$-( $\Delta^{2}$-isopentenyl)adenine 9-glucoside. The system of cytokinin abbreviations is adopted and modified according to Kamínek et al. ${ }^{6}$. Structural formulas are adapted according to Bajguz and Piotrowska ${ }^{5}$. 


\begin{tabular}{|c|c|c|c|c|c|c|}
\hline Publication & Tissue & Hormone & $\begin{array}{l}\text { Endogenous } \\
\text { amount reported }\end{array}$ & In pmol/g tissue & \begin{tabular}{|l} 
Cultivar \\
or subspecies
\end{tabular} & Grown \\
\hline \multirow{10}{*}{ Schmülling et al..$^{24}$} & \multirow{5}{*}{ shoots } & IAA & $962 \mathrm{pmol} / \mathrm{gFW}$ & & \multirow{10}{*}{$\begin{array}{l}\text { T342 } \\
\text { ("empty" } \\
\text { transformation } \\
\text { vector) }\end{array}$} & \multirow{10}{*}{ greenhouse } \\
\hline & & ABA & $112 \mathrm{pmol} / \mathrm{gFW}$ & & & \\
\hline & & tZR & $9.2 \mathrm{pmol} / \mathrm{gFW}$ & & & \\
\hline & & DHZR & $4.1 \mathrm{pmol} / \mathrm{gFW}$ & & & \\
\hline & & iPR & $2.9 \mathrm{pmol} / \mathrm{gFW}$ & & & \\
\hline & \multirow{5}{*}{ roots } & IAA & $975 \mathrm{pmol} / \mathrm{gFW}$ & & & \\
\hline & & $\mathrm{ABA}$ & $37 \mathrm{pmol} / \mathrm{gFW}$ & & & \\
\hline & & $t \mathrm{ZR}$ & $3.1 \mathrm{pmol} / \mathrm{gFW}$ & & & \\
\hline & & DHZR & $2.0 \mathrm{pmol} / \mathrm{gFW}$ & & & \\
\hline & & iPR & $4.2 \mathrm{pmol} / \mathrm{gFW}$ & & & \\
\hline \multirow{9}{*}{ Dermastia et al..$^{25}$} & \multirow{9}{*}{ whole plantlets } & $t Z$ & $10.0 \mathrm{pmol} / \mathrm{gFW}$ & & \multirow{9}{*}{ Sante } & \multirow{9}{*}{ in vitro } \\
\hline & & DHZ & $9.5 \mathrm{pmol} / \mathrm{gFW}$ & & & \\
\hline & & iP & not detected & & & \\
\hline & & tZR & $164.2 \mathrm{pmol} / \mathrm{gFW}$ & & & \\
\hline & & DHZR & $17.5 \mathrm{pmol} / \mathrm{gFW}$ & & & \\
\hline & & iPR & $55.8 \mathrm{pmol} / \mathrm{gFW}$ & & & \\
\hline & & $t \mathrm{Z9G}$ & $21.6 \mathrm{pmol} / \mathrm{gFW}$ & & & \\
\hline & & DHZ9G & $35.5 \mathrm{pmol} / \mathrm{gFW}$ & & & \\
\hline & & iP9G & $44.2 \mathrm{pmol} / \mathrm{gFW}$ & & & \\
\hline \multirow{2}{*}{ Yakovleva et al. ${ }^{26}$} & \multirow{2}{*}{ leaves } & $t \mathrm{Z}$ & $2-16 \mathrm{ng} / \mathrm{gFW}$ & 9-73 pmol/gFW & \multirow{2}{*}{ Kamyk } & \multirow{2}{*}{ in vitro } \\
\hline & & $t \mathrm{ZR}$ & 6-15 ng/gFW & $17-43 \mathrm{pmol} / \mathrm{gFW}$ & & \\
\hline \multirow{6}{*}{ Macháčková et al..$^{27}$} & \multirow{6}{*}{ shoots } & IAA & $14.2 \mathrm{ng} / \mathrm{gFW}$ & $81 \mathrm{pmol} / \mathrm{gFW}$ & \multirow{6}{*}{ Miranda } & \multirow{6}{*}{ in vitro } \\
\hline & & $\mathrm{ABA}$ & $200-300$ ng/gFW & $\begin{array}{l}750-1150 \mathrm{pmol} / \\
\text { gFW }\end{array}$ & & \\
\hline & & $t Z$ & $11.2 \mathrm{ng} / \mathrm{gFW}$ & $51 \mathrm{pmol} / \mathrm{gFW}$ & & \\
\hline & & iP & $10.1 \mathrm{ng} / \mathrm{gFW}$ & $50 \mathrm{pmol} / \mathrm{gFW}$ & & \\
\hline & & $t \mathrm{ZR}$ & $20.1 \mathrm{ng} / \mathrm{gFW}$ & $57 \mathrm{pmol} / \mathrm{gFW}$ & & \\
\hline & & iPR & $12.5 \mathrm{ng} / \mathrm{gFW}$ & $37 \mathrm{pmol} / \mathrm{gFW}$ & & \\
\hline \multirow{4}{*}{ Macháčková et al..$^{28}$} & \multirow{2}{*}{ shoots } & IAA & $200-400$ ng/gFW & $\begin{array}{l}1100-2300 \mathrm{pmol} / \\
\mathrm{gFW}\end{array}$ & \multirow{4}{*}{$\begin{array}{l}\text { S. tuberosum } \\
\text { ssp. andigena }\end{array}$} & \multirow{4}{*}{ greenhouse } \\
\hline & & ABA & $10-25 \mathrm{ng} / \mathrm{gFW}$ & 38-95 pmol/gFW & & \\
\hline & \multirow[t]{2}{*}{ leaves } & IAA & $200-250$ ng/gFW & $\begin{array}{l}1100-1400 \mathrm{pmol} / \\
\mathrm{gFW}\end{array}$ & & \\
\hline & & ABA & $10-40$ ng/gFW & $38-150 \mathrm{pmol} / \mathrm{gFW}$ & & \\
\hline De Jong et al. ${ }^{29}$ & leaves & $\mathrm{ABA}$ & $300-560 \mathrm{ng} / \mathrm{gDW}$ & $\begin{array}{l}1100-2100 \mathrm{pmol} / \\
\mathrm{gDW}\end{array}$ & not stated & greenhouse \\
\hline Muñiz García et al. ${ }^{30}$ & leaves & $\mathrm{ABA}$ & $68.2 \mathrm{ng} / \mathrm{gFW}$ & $258 \mathrm{pmol} / \mathrm{gFW}$ & Spunta & in vitro \\
\hline \multirow{9}{*}{ Kolachevskaya et al. ${ }^{31-33}$} & \multirow{9}{*}{ shoots } & IAA & $332 \mathrm{pmol} / \mathrm{gDW}$ & & & \\
\hline & & $\mathrm{ABA}$ & $2089 \mathrm{pmol} / \mathrm{gDW}$ & & & \\
\hline & & $c \mathrm{Z}$ & $104 \mathrm{pmol} / \mathrm{gDW}$ & & & \\
\hline & & $t Z$ & $58.5 \mathrm{pmol} / \mathrm{gDW}$ & & & \\
\hline & & iP & $206 \mathrm{pmol} / \mathrm{gDW}$ & & Désirée & in vitro \\
\hline & & $c \mathrm{ZR}$ & $1535 \mathrm{pmol} / \mathrm{gDW}$ & & & \\
\hline & & tZR & $404 \mathrm{pmol} / \mathrm{gDW}$ & & & \\
\hline & & \begin{tabular}{|l|} 
DHZR \\
\end{tabular} & $56.1 \mathrm{pmol} / \mathrm{gDW}$ & & & \\
\hline & & iPR & $3329 \mathrm{pmol} / \mathrm{gDW}$ & & & \\
\hline
\end{tabular}

Table 1. Endogenous levels of particular cytokinin molecules and indole-3-acetic acid (IAA) and abscisic acid (ABA) in various tissues of potato, as reported in available literature data. Type of tissue where endogenous phytohormones were measured, potato cultivar and growth conditions (greenhouse or in vitro) are disclosed for each measurement. For scientific reports where control plants or tissues were compared to plants or tissues that had undergone specific treatments, only values corresponding to control plants or tissues are provided. The system of cytokinin abbreviations is adopted and modified according to Kamínek et al.6. FW = fresh weight; $\mathrm{DW}=$ dry weight.

\section{Results}

The composition of endogenous CKs in shoots and roots of potato plants grown in vitro is summarised in Fig. 2. Total CK amount in the roots $(851.9 \pm 16.4 \mathrm{pmol} / \mathrm{gFW})$ was almost double as abundant as in shoots $(467.1 \pm 5.8$ $\mathrm{pmol} / \mathrm{gFW}$ ). The most abundant group of CKs in both shoots and roots were $N$-glucosides, accounting for $94 \%$ of total CK pool in the shoots and $82 \%$ in the roots, while bioactive CK nucleobases comprised only a small portion 
a

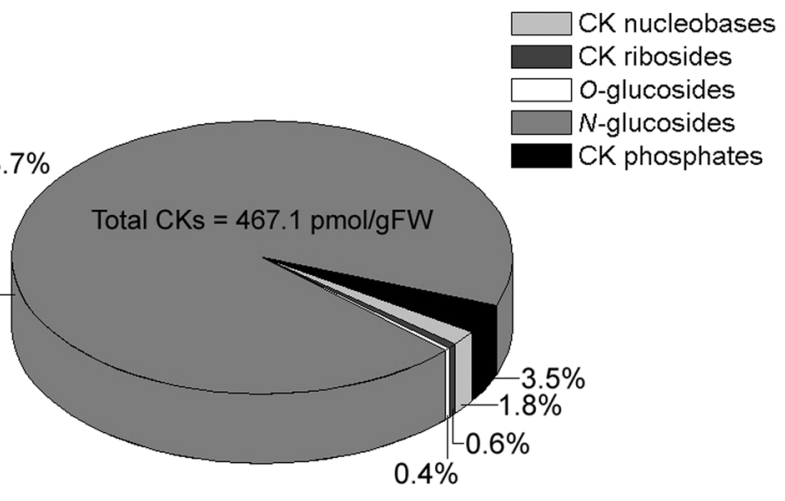

b

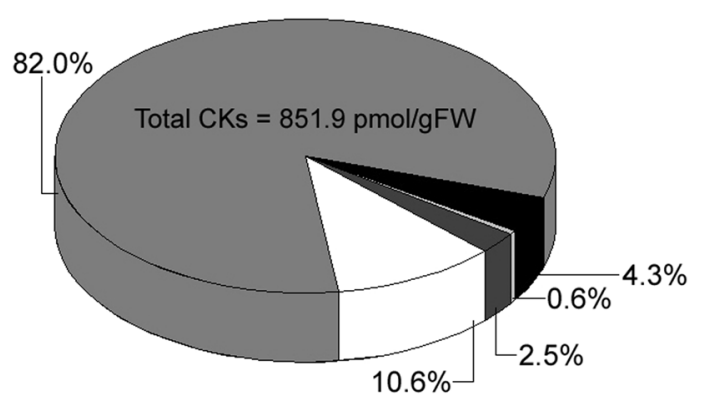

Figure 2. Quantitative composition of endogenous cytokinins in shoots (a) and roots (b) of 30 day old in vitro grown potato (Solanum tuberosum L. cv. Désirée) plants. The absolute amount of total cytokinins for each tissue is shown inside each of the two pie charts. Data represent means of three biological replicates.

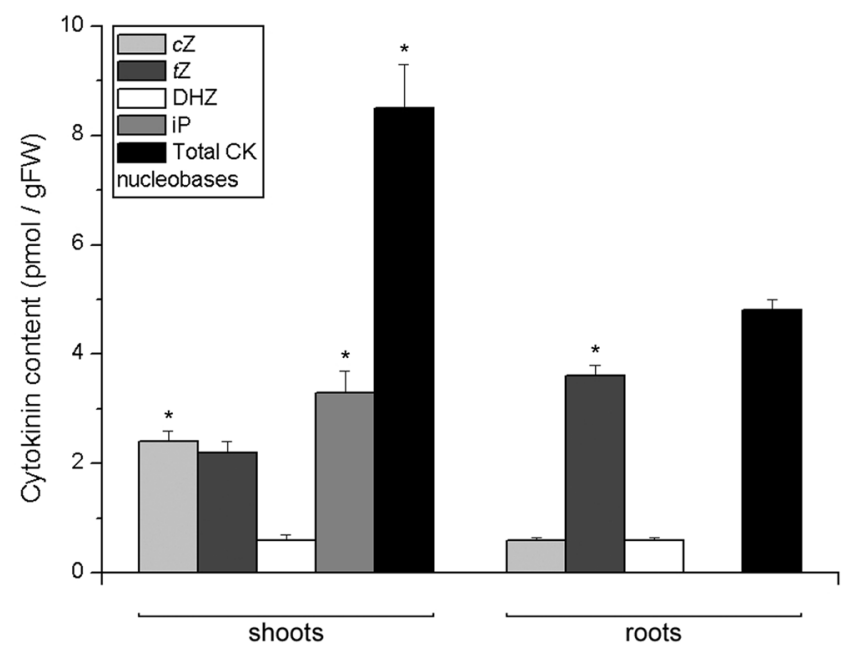

Figure 3. Endogenous levels of cytokinin nucleobases in shoots (left) and roots (right) of 30 day old in vitro grown potato (Solanum tuberosum L. cv. Désirée) plants. Data represent means \pm standard errors $(n=3)$. Asterisks $(*)$ are used to indicate the tissue with the higher prevalence of a CK molecule, where differences between shoot and root content are statistically significant $(P<0.05$ according to Student's $t$-test).

of total CK content in both shoots and roots of potato.

Endogenous levels of CK nucleobases in shoots and roots of potato plants are shown in Fig. 3. Their amount in shoots was significantly higher than in roots. The most abundant CK nucleobase in the shoots was iP, closely followed by $c Z$ and $t Z$, while DHZ was less abundant. In the roots, the most abundant nucleobase was $t Z$; endogenous levels of $c \mathrm{Z}$ and $\mathrm{DHZ}$ were much lower, while iP was not detected in potato roots in our experiment.

To the contrary from nucleobases, CK ribosides were around 8 times more abundant in potato roots than in shoots (Fig. 4). The most abundant riboside in potato shoots was $t$ ZR, followed by $c Z R$ and iPR, while DHZR was present barely at the detection level. In roots, the two isoforms of zeatin ribosides, $c Z R$ and $t Z R$ accounted for most of the high levels of CK ribosides, while iPR was much less abundant and DHZR barely at the detection level. 


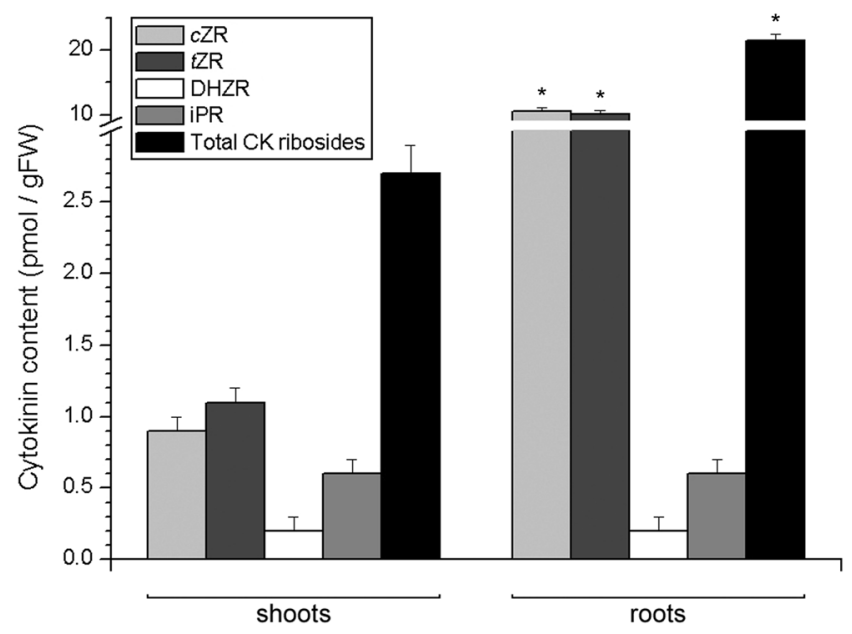

Figure 4. Endogenous levels of cytokinin ribosides in shoots (left) and roots (right) of 30 day old in vitro grown potato (Solanum tuberosum L. cv. Désirée) plants. Data represent means \pm standard errors $(n=3)$. Asterisks $(*)$ are used to indicate the tissue with the higher prevalence of a CK molecule, where differences between shoot and root content are statistically significant $(P<0.05$ according to Student's $t$-test).

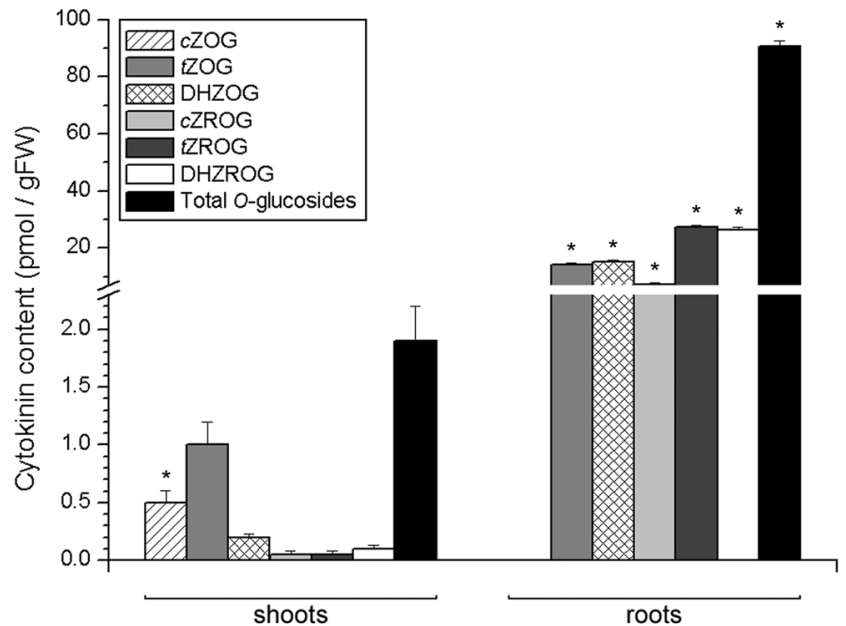

Figure 5. Endogenous levels of cytokinin $O$-glucosides in shoots (left) and roots (right) of 30 day old in vitro grown potato (Solanum tuberosum L. cv. Désirée) plants. Data represent means \pm standard errors $(n=3)$. Asterisks (*) are used to indicate the tissue with the higher prevalence of a CK molecule, where differences between shoot and root content are statistically significant $(P<0.05$ according to Student's $t$-test).

Cytokinin $O$-glucosides were almost 50 times more abundant in roots than in shoots of potato (Fig. 5). In potato shoots, $t Z O G$ was the most abundant $O$-glucoside, followed by $c Z O G$, while other $O$-glucosides were present at less than $0.2 \mathrm{pmol} / \mathrm{gFW}$ each. In roots, the most abundant $O$-glucosides were $t$ ZROG and DHZROG, accounting for nearly one-third of the total amount of $O$-glucosides each, while DHZOG, $t Z$ ZOG and $c Z R O G$ accounted for the rest, and $c$ ZOG was not detected.

Cytokinin $\mathrm{N}$-glucosides represented the most abundant type of CKs in potato. Endogenous levels of N7- and N9-glucosides are presented in Fig. 6a,b, respectively. Remarkably high levels of N7-glucosides accounted for $99.1 \%$ of total $N$-glucosides (and $92.9 \%$ of total CKs) in the shoots, and $93.3 \%$ of total $N$-glucosides (and $76.5 \%$ of total CKs) in the roots of potato (Fig. 6a). Half of the total N7-glucosides in the shoots was comprised by iP7G, followed by $t Z 7 G, c Z 7 G$ and DHZ7G. In the roots, the dominant $N 7$-glucoside was $t Z 7 G$, accounting for around half of the total N7-glucosides, and followed by DHZ7G, while iP7G and $c Z 7 G$ were relatively less abundant, although still present at high levels (Fig. 6a). Of the N9-glucosides, $c Z 9 G$ was the most abundant in the shoots, followed by iP9G and $t Z 9$ G, while DHZ9G was not detected. Differently from the shoots, DHZ9G was the most abundant N9-glucoside in the roots, followed by $c Z 9 G$, while iP9G and $t$ Z9G were somewhat less abundant. All the N9-glucosides had significantly higher levels in roots than in shoots (Fig. 6b).

Cytokinin phosphates in potato roots were more than double as abundant as in shoots (Fig. 7). The most abundant in both tissues were $t Z$-phosphates, accounting for $63 \%$ of all CK phosphates in the shoot and $80 \%$ in the root. They were followed by iP-phosphates in both tissues, while $c Z$-phosphates and DHZ-phosphates were 

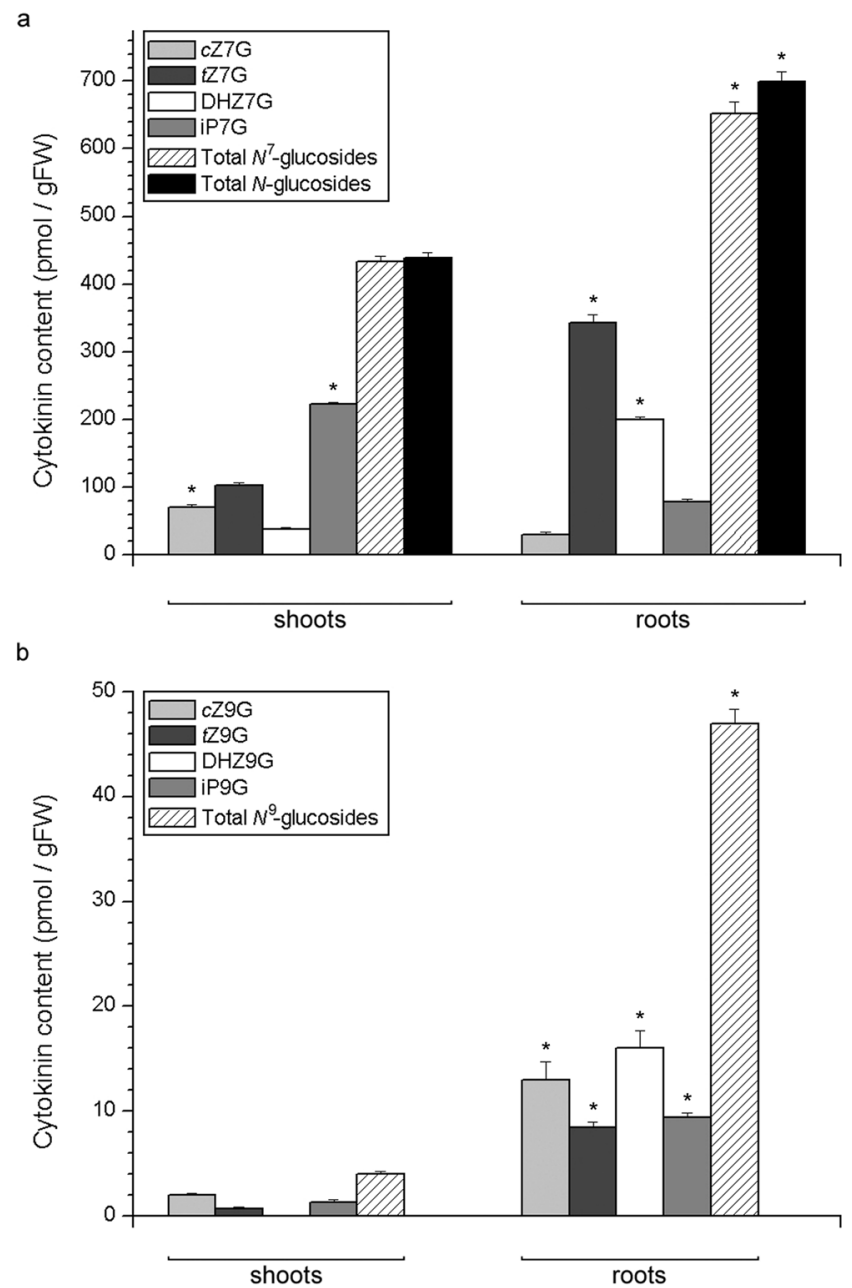

Figure 6. Endogenous levels of cytokinin $N$-glucosides in shoots and roots of 30 day old in vitro grown potato (Solanum tuberosum L. cv. Désirée) plants. Total $N$-glucosides (a) are dominantly comprised of N7-glucosides (a) while N9-glucosides (b) are present in much lower amounts. Data represent means \pm standard errors $(n=3)$. Asterisks (*) are used to indicate the tissue with the higher prevalence of a CK molecule, where differences between shoot and root content are statistically significant $(P<0.05$ according to Student's $t$-test).

less abundant. The levels of $t$ Z-phosphates and DHZ-phosphates were significantly higher in the roots compared to shoots.

Endogenous content of IAA as the most important naturally occurring auxin, is shown in Table 2. There was no statistically significant difference between endogenous levels of IAA in shoots and roots, but the IAA/CK nucleobase ratio was significantly higher in roots (13.0) than in shoots (9.6). Table 2 also shows the endogenous levels of ABA, which were significantly higher in shoots $(251.9 \mathrm{pmol} / \mathrm{gFW})$ than in roots $(124.3 \mathrm{pmol} / \mathrm{gFW})$, while no significant difference between shoots and roots was shown for the ABA/CK nucleobase ratio.

\section{Discussion}

Potato (Solanum tuberosum L.) is the world's fourth most important crop species, after maize, wheat and rice. Its worldwide production in 2017 amounted to 388 million tonnes grown on 19.3 million hectares (http://www.fao. org/faostat/en/\#data/QC). The economic importance of potato has motivated extensive research in the area of potato biology, including the recent sequencing of the $844 \mathrm{Mbp}$-large potato genome $\mathrm{e}^{37}$.

Particular research attention has focused on the process of tuberisation in potato, both for its economic importance, and for the suitability of potato as a model system for this physiological trait that is not widespread in the plant world. Phytohormones have been considered major players in regulating tuberisation. Gibberellins have been the first group of hormones shown to be importantly involved in tuberisation ${ }^{38}$, but in the recent years growing attention has been paid also to other groups of phytohormones, primarily CKs and auxins ${ }^{18-23}$. It has been suggested that endogenous bioactive CKs affect tuber induction, as CK-deficient potato plants overexpressing genes for cytokinin oxidase/dehydrogenase, an enzyme involved in CK catabolism, were able to undergo tuberisation before the $30^{\text {th }}$ day of growth in "long days" ( $16 \mathrm{~h}$ light $/ 8 \mathrm{~h}$ darkness photoperiod), which never happens in wild-type plants ${ }^{22,23}$. The recent increase in research interest for CKs and auxins in potato and their supposed role in tuberisation has resulted in novel developments in potato physiology, most notably the identification of the three CK receptor genes in diploid Phureja potato (orthologous to the three CK receptor genes of Arabidopsis), 


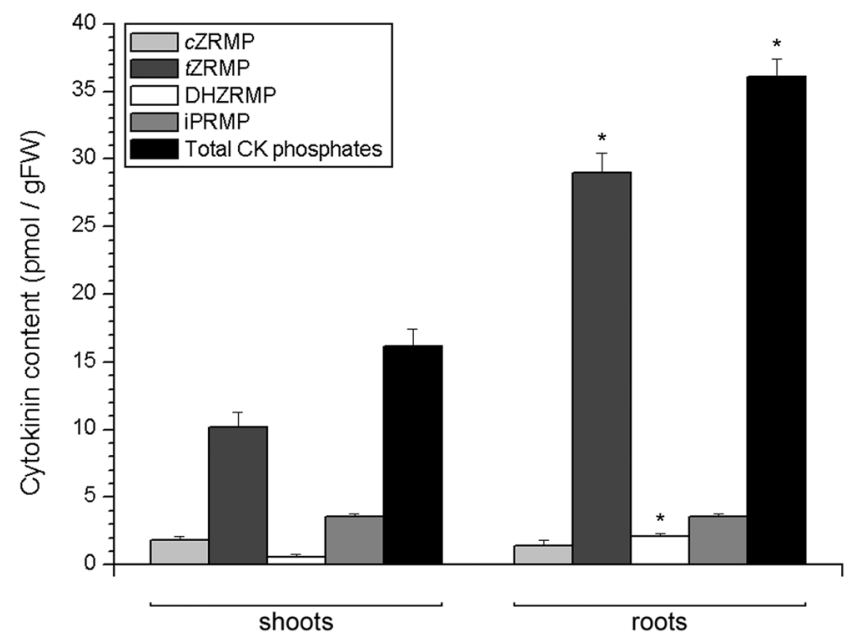

Figure 7. Endogenous levels of cytokinin phosphates in shoots (left) and roots (right) of 30 day old in vitro grown potato (Solanum tuberosum L. cv. Désirée) plants. Data represent means \pm standard errors $(n=3)$. Asterisks $(*)$ are used to indicate the tissue with the higher prevalence of a CK molecule, where differences between shoot and root content are statistically significant $(P<0.05$ according to Student's $t$-test $)$.

\begin{tabular}{|l|c|c|}
\hline Plant hormone & Shoots & Roots \\
\hline IAA $(\mathrm{pmol} / \mathrm{gFW})$ & $82.0 \pm 19.0$ & $62.3 \pm 11.9$ \\
\hline IAA/CK nucleobase ratio & $9.6 \pm 2.2$ & $13.0 \pm 2.5^{*}$ \\
\hline $\mathrm{ABA}(\mathrm{pmol} / \mathrm{gFW})$ & $251.9 \pm 14.9^{*}$ & $124.3 \pm 7.8$ \\
\hline $\mathrm{ABA} / \mathrm{CK}$ nucleobase ratio & $29.6 \pm 1.8$ & $25.9 \pm 1.6$ \\
\hline
\end{tabular}

Table 2. Endogenous levels of indole-3-acetic acid (IAA) and abscisic acid (ABA) in shoots and roots of 30 day old in vitro grown potato plants, and their ratio to the endogenous level of cytokinin nucleobases in respective tissues. Asterisks $\left(^{*}\right)$ are used to indicate the greater of the two values, where differences between shoot and root are statistically significant $(P<0.05$ according to Student's $t$-test).

and cloning and characterisation of the six receptor genes in the autotetraploid cultivar Désirée ${ }^{39}$. On the other hand, literature data concerning the CK hormonomics of potato have only been partial, containing little or no information about particular molecular forms such as $\mathrm{O}$ - and $\mathrm{N}$-glucosides, and heterogenous from the point of view of the cultivars being investigated, as well as cultivation conditions.

In the present study, endogenous levels of isoprenoid CKs were determined in shoots and roots of 30 day old in vitro grown potato plants of the cultivar Désirée. In addition, endogenous levels of the auxin IAA have been measured for its close relation to CK physiology, and levels of ABA have been determined as an indicator of exposure to stress, for the sake of comparison to the results of other studies where potato plants were grown in vitro or ex vitro. Plants grown in vitro were chosen for this investigation over soil-grown plants for the sake of reproducibility of the results. Phytohormone measurements carried out on plants grown in vitro are expected to be more reproducible between studies, in comparison to measurements on greenhouse- or field-grown plants, where endogenous levels of various phytohormones can be subject to considerable variations depending on environmental conditions such as soil quality and composition, temperature, light regime, or air moisture.

Our results revealed that the total CK levels amounted to $467.1 \mathrm{pmol} / \mathrm{gFW}(173.9 \mathrm{ng} / \mathrm{gFW})$ in potato shoots and $851.9 \mathrm{pmol} / \mathrm{gFW}$ (332.4 ng/gFW) in the roots (Fig. 2), considerably less than $1-100 \mu \mathrm{g} / \mathrm{gFW}$ which is considered a typical range for total CK levels in tissues of vascular plants ${ }^{4}$. Values that are even considerably lower than those presented here, have been reported for seedlings of basal-media grown kohlrabi (Brassica oleracea var. gongylodes $)^{40}$ and for in vitro grown centaury (Centaurium erythraea Rafn. $)^{41}$. Also, higher values for total endogenous CKs in the roots of potato compared to the shoots, are consistent with the observation that roots are generally more abundant in CKs, being their primary site of synthesis ${ }^{42}$.

Cytokinin nucleobases comprised a low proportion of total CK levels in both shoots (1.8\%) and roots $(0.6 \%)$ of potato, while $N$-glucosides, which are widely considered to be irreversibly inactive, accounted for $94 \%$ of the total CK pool in the shoots and $82 \%$ in the roots (Fig. 2). A similar pattern was found in CK composition of C. erythraea ${ }^{41}$, indicating that the utilisation of only a small portion of total CKs is a common phenomenon at least among asterids, if not in broader groups of plants.

Cytokinin nucleobases were more abundant in potato shoots than in roots (Fig. 3). The most abundant CK nucleobase in the shoots in our study was iP, while in the roots it was $t \mathrm{Z}$. iP was previously shown to be the most abundant CK nucleobase in potato shoots ${ }^{32,33}$. It has been shown that the biological activity of iP is important for physiological processes in plant shoots ${ }^{43}$. On the other hand, $t Z$ is important for signalling processes in the root. In maize, $t Z, t Z R$ and $t Z$-phosphates activate the transcription of the gene $Z m R R 1$ to mediate the uptake of nitrogene from the soil, whereas iP-type CKs are not likely implicated in this signalling pathway ${ }^{44}$. There is 
considerable evidence for tissue-specific conversion of iP- to $t$ Z-type CKs occurring predominantly in the roots of Arabidopsis, providing a plausible explanation for a preferential accumulation of iP in the shoot, but $t Z$ in the root tissue of this species ${ }^{10,45,46}$. The composition of CK nucleobases in the respective tissues of potato thus suggests substantial similarities with the tissue-specific patterns of CK biosynthesis and metabolism as reported in Arabidopsis.

Unlike nucleobases, CK ribosides were remarkably more abundant in potato roots than in shoots (Fig. 4). The same has been observed in C. erythraea ${ }^{41}$. The most abundant CK riboside in potato shoots was $t \mathrm{ZR}$, and it was also remarkably abundant in the roots. In previous studies ${ }^{25,27} \mathrm{tZR}$ was also the most abundant CK riboside in potato. This particular CK molecule is important for root-to-shoot communication in plants, being the most abundant CK transported through the xylem sap as has been documented in a number of studies ${ }^{44,47,48}$. The essential role of $t Z$-type CKs for long-distance signalling was confirmed in Arabidopsis, where loss of function of the ABCG14 transporter, responsible for CK root-to-shoot transport, caused a decrease in levels of shoot $t \mathrm{Z}$ - and DHZ- type CKs, but not iP-types ${ }^{49,50}$.

The almost 50-fold difference between potato roots and shoots in endogenous levels of $O$-glucosides (Fig. 5) suggests that roots are the primary CK storage site in potato. It has been suggested that $O$-glucosylation, as well as $N$-glucosylation and possibly $O$-xylosylation, may be activated as a protective mechanism against CK degradation in potato plants that overexpress the genes for cytokinin oxidase/dehydrogenase ${ }^{21-23}$, thus underlining the biological importance of $O$-glucosides for maintaining hormonal homeostasis in potato.

$\mathrm{N}$-glucosides were the most dominant CK forms, accounting for the bulk of the total CK pool in both shoots and roots of potato (Figs. 2 and 6). This large prevalence of $N$-glucosides was mostly due to $N 7$-glucosides, which made up for $99.1 \%$ of total $N$-glucosides in potato shoots and $93.3 \%$ in the roots (Fig. 6a), while N9-glucosides were much less abundant (Fig. 6b). Interestingly, $\mathrm{N}$-glucosides represented also the dominant CK type in $\mathrm{C}$. erythraea, but to the contrary from potato, the bulk of centaury's $\mathrm{N}$-glucosides was comprised by $\mathrm{N} 9$-glucosides, whereas those glucosylated at the $N^{7}$-position made up for barely more than $10 \%$ of total $N$-glucosides in both shoots and roots of centaury ${ }^{41}$. Apparently, although both species accumulate large amounts of CK $N$-glucosides (which is therefore likely to be a common feature in plants), the preference for accumulating N7- versus N9-glucosides is probably specific to particular taxa. In Arabidopsis, the enzymes UGT76C1 and UGT76C2, which are responsible for CK $N$-glucosylation, both prefer $N 7$ - to $N 9$-glucosylation, accordingly with the relative amounts of N7- and N9-glucosides in various tissues of Arabidopsis ${ }^{4}$. If similar investigations are carried out to determine the CK profiles of other plant species, preferential patterns of accumulation of various CK types could provide us with interesting new insights regarding phylogenetic differences in CK metabolism.

Cytokinin phosphates accounted for around $4 \%$ of total CKs in both shoots and roots of potato (Fig. 7). The most abundant type of CK phosphates in both shoots and roots of potato were $t Z$ phosphates. Although iPRMP was present in both shoots and roots at $3.6 \mathrm{pmol} / \mathrm{gFW}$, $t$ ZRMP was much more abundant in roots than in shoots, therefore rendering the $t$ ZRMP:iPRMP ratio higher in roots than in shoots. In Arabidopsis, biosynthesis of $t Z$-type CKs occurs through the hydroxylation of iP mono-, di- and triphosphates into respective $t Z$ phosphates, by means of the enzymes of the CYP735A family. Conversion of iP phosphates into $t Z$ phosphates was more intense in roots, than in leaves and shoots of Arabidopsis ${ }^{45}$. The $t$ ZRMP:iPRMP ratio found in shoots and roots of potato thus indicates similarities with the tissue-specific patterns of the biosynthesis of $t$ Z-type CKs as observed in Arabidopsis.

Taken together, differences in CK composition between shoots and roots of potato suggest specific patterns of CK transport, and/or differences in tissue-specific metabolism of these hormones. Certain patterns might not only be tissue-specific, but also remarkably specific for a particular molecular form. For instance, $c Z O G$ was the only $O$-glucoside that is completely missing in the roots, whereas all other $O$-glucosides were present well over the detection threshold (Fig. 5). At the same time, $c Z O G$ was the second most abundant $O$-glucoside in the shoots, accounting for ca. a quarter of all $O$-glucosides. Whether $c Z O G$ might be metabolised in the roots or transported elsewhere, this phenomenon appears to be highly specific and to apply only to $c Z O G$, but not, for instance, $t$ ZOG or $c$ ZROG. Similarly, DHZ9G was the most abundant N9-glucoside in the roots, while being completely absent in shoots (Fig. 6b). It has already been suggested that metabolic pathways of cis- and trans-zeatin type CKs might be at least partly separated from each other thanks to fine-tuned substrate specificity of enzymes involved in their metabolism, e.g., in glucosylation ${ }^{51}$; as most of these enzymes are activated in a tissue-specific ${ }^{12}$ or development-related ${ }^{47}$ fashion, it is likely that their substrate specificity reflects on the CK composition of respective plant tissues. Possible tissue-specific mechanisms of metabolism and transport that might underlie specific differences between shoots and roots on the level of individual molecular forms of CKs, deserve special attention and require sophisticated research approaches specifically targeting each type of CK molecule.

Our results for endogenous IAA content $(82.0 \mathrm{pmol} / \mathrm{gFW}$ in shoots and $62.3 \mathrm{pmol} / \mathrm{gFW}$ in roots $)$ were similar to others reported for in vitro grown potato ${ }^{27,31,33}$ but considerably lower than those found in greenhouse-grown plants ${ }^{24}$. It has been reported that the IAA content of in vitro grown shoots of the potato cultivar Miranda amounted to $81 \mathrm{pmol} / \mathrm{gFW}^{27}$. Also, more recent data ${ }^{31,33}$ for the level of IAA in in vitro grown shoots of the cultivar Désirée can be considered more or less corresponding to the result reported for the same cultivar in our study, having in mind that DW content values are supposed to be several-fold higher than FW values.

IAA is the auxin whose endogenous content is most commonly reported in plant physiology research, and its physiological effects and metabolic regulation are considered largely interconnected with the physiology of $\mathrm{CKs}^{5}$. Auxins and CKs are known to regulate each other's endogenous levels, forming a feedback loop ${ }^{52-55}$. The ratio between endogenous levels of IAA and bioactive CKs is considered more relevant to a number of physiological processes in plants, than the individual levels of each of these hormones alone ${ }^{56}$. The IAA/CK nucleobase ratio in this work was lower in shoots (9.6) than in roots (13.0) of potato (Table 2). The opposite relation has been observed between IAA/CK nucleobase ratios in shoots and roots of centaury, which might be relevant to the capacity of this species to undergo spontaneous de novo shoot organogenesis (DNSO) from roots on 
hormone-free media ${ }^{41}$, which has not been observed in potato. A high endogenous IAA/bioactive CK levels ratio was considered relevant to the ability of kohlrabi seedlings to successfully undergo DNSO on auxin-free media, contrary to hypocotyl explants which had a significantly lower IAA/bioactive CK ratio ${ }^{40}$. On the other hand, Kufri Sutlej, a potato cultivar with naturally high endogenous auxin levels, was able to produce only callus in standard regeneration protocols and required the addition of an anti-auxin to the regeneration media in order to regenerate shoots ${ }^{57}$.

Most previous studies on in vitro grown potato plants reported higher endogenous levels of bioactive ABA compared to results obtained for greenhouse-grown plants (Table 1), but all of them lacked data on the content of ABA metabolites and conjugates, which can be determined using LC-MS/MS as the quantification method, rather than HPLC $^{58}$. The physiological balance between biosynthesis and catabolism of ABA is highly dynamic, making the measurements of its metabolites and conjugates useful to complement the information on the time profile of ABA levels, in settings where the fluctuations of ABA in time are relevant ${ }^{59,60}$ - for instance, data on endogenous levels of ABA and its metabolites in defoliated and decapitated potato shoot segments were recently published in a study on the circadian dynamics of phototropic bending in potato ${ }^{61}$.

However, in this study we were mainly interested in determining the bioactive ABA in order to compare to previous reports. The endogenous levels of ABA in potato shoots in this work were similar to those in the leaves of in vitro grown plants of the cultivar Spunta ${ }^{30}$ and in the shoots of the cultivar Désiré ${ }^{33}$. Lower endogenous levels of ABA were reported in shoots of greenhouse-grown potato plants ${ }^{24,28}$. There is considerable evidence that the endogenous levels of bioactive ABA are elevated in plants exposed to environmental stress ${ }^{62,63}$. Plants grown in vitro have already been widely considered to be exposed to chronic multiple stress. It has been shown that in vitro grown potato plants are exposed to lower light intensity and altered composition of light spectrum ${ }^{64}$, greater relative humidity ${ }^{65}$, poor or no aeration of the culture vessels resulting in accumulation of ethylene in the proximity of cultured plants ${ }^{66}$, and altered balance between heterotrophic and autotrophic carbon assimilation ${ }^{67}$. Constant exposure to multiple stress might thus contribute to increased levels of ABA in in vitro grown potato.

In conclusion, we determined the endogenous levels of CKs, as well as IAA and ABA, in shoots and roots of 30 day old in vitro grown potato (cv. Désirée) plants. Although endogenous phytohormone levels of potato plants, grown either in vitro or ex vitro, have been reported in a number of publications to date, our report is the first where all analytically detectable forms of isoprenoid CKs, including molecular conjugates and $c Z$-type CKs, are presented individually. Our results are generally similar to other reports on in vitro grown potato, whereas greenhouse-grown potato plants typically have lower ABA content. Differences in phytohormone composition between shoots and roots of potato suggest specific patterns of transport and/or differences in tissue-specific metabolism of plant hormones. This report represents an important step in elucidating the hormonomics of potato, a crop species which is being extensively studied because of its great agronomic importance in the $21^{\text {st }}$ century.

\section{Methods}

Plant material. Virus-free potato tubers (Solanum tuberosum L. cv. Désirée) obtained from the PKB Agroeconomic Institute (Belgrade, Serbia), were used to establish shoot cultures from sprouts, as previously described ${ }^{68}$. Tissue cultures were propagated in vitro every four weeks from single-node stem cuttings as described in our previous work ${ }^{22}$. Cultivation media, consisting of MS basal salts ${ }^{69}$, were solidified with $0.7 \%$ agar and supplemeted with $3 \%$ sucrose, $0.1 \%$ inositol, and vitamins ${ }^{70}$. The cultivation chamber was set at $25 \pm 2{ }^{\circ} \mathrm{C}$, $16 \mathrm{~h} / 8 \mathrm{~h}$ light/dark photoperiod with white fluorescent lamps ("Philips TL-D $58 \mathrm{~W} / 54-765$ ”, $58 \mathrm{~W}, 6200 \mathrm{~K}, 50$ $\mu \mathrm{mol} \mathrm{m}{ }^{-2} \mathrm{~s}^{-1}$, Philips, Amsterdam, The Netherlands). Shoots and roots were isolated from 30 day old plantlets from in vitro culture, frozen in liquid nitrogen and subjected to phytohormone extraction.

Phytohormone extraction and quantification. Plant material (1 gFW of potato shoot and root tissue each) was homogenised in liquid nitrogen with a mortar and pestle and extracted in a mixture of methanol, formic acid and water (15:1:4, v/v/v). Purification was carried out using the dual-mode solid-phase extraction method $^{71}$. Concentration of CK phosphates (nucleotides) was determined as corresponding ribosides following dephosphorylation by alkaline phosphatase. Detection and quantification were carried out on a HPLC/MS system LCQ (Finnigan, San José, CA, USA) operated in the positive-ion full-scan MS/MS mode using a multilevel calibration graph with $\left[{ }^{2} \mathrm{H}\right]$-labelled CKs as internal standards. The list of used $\left[{ }^{2} \mathrm{H}\right]$-labelled standards is given in Supplementary Table S1. Detection limits varied between 0.05 and $0.1 \mathrm{pmol} / \mathrm{sample}$ for various CKs. Endogenous levels of free (non-hydrolysed) IAA and ABA were determined by two-dimensional HPLC (first dimension: TSP, Riviera Beach, FL, USA; second dimension: Perkin Elmer, Wellesley, MA, USA) as previously described ${ }^{72}$. Quantification of IAA was carried out with a fluorescence detector LC 240, while ABA was quantified on the basis of ultraviolet detection with a diode array detector 235C (both manufactured by Perkin Elmer).

Statistical analysis. Endogenous phytohormone levels were measured in three biological replicates for both shoot and root. Each measurement was repeated twice with similar results. The results are presented as means of biological replicates \pm SE based on statistical analysis performed with Statgraphics Plus Version 2.1 (Statpoint Technologies Inc., Warrenton, VA, USA) with statistical differences between the means determined by Student's $t$-test. Graphs were designed with Origin 6.1 (OriginLab Corporation, Northampton, MA, USA).

Received: 29 October 2019; Accepted: 7 February 2020;

Published online: 26 February 2020 


\section{References}

1. Santner, A., Calderon-Villalobos, L. I. A. \& Estelle, M. Plant hormones are versatile chemical regulators of plant growth. Nat. Chem. Biol. 5, 301-307 (2009).

2. Hagihara, S., Yamada, R., Itami, K. \& Torii, K. U. Dissecting plant hormone signaling with synthetic molecules: perspective from the chemists. Curr. Opin. Plant Biol. 47,32-37 (2019).

3. Mok, D. W. S. \& Mok, M. C. Cytokinin metabolism and action. Annu. Rev. Plant Physiol. Plant Mol. Biol. 52, 89-118 (2001).

4. Sakakibara, H. Cytokinins: Activity, biosynthesis, and translocation. Annu. Rev. Plant Biol. 57, 431-449 (2006).

5. Bajguz, A. \& Piotrowska, A. Conjugates of auxin and cytokinin. Phytochemistry 70, 957-969 (2009).

6. Kamínek, M. et al. Purine cytokinins: a proposal of abbreviations. Plant Growth Regul. 32, 253-256 (2000).

7. Stirk, W. A. et al. Involvement of cis-zeatin, dihydrozeatin, and aromatic cytokinins in germination and seedling establishment of maize, oats, and lucerne. J. Plant Growth Regul. 31, 392-405 (2012).

8. Lomin, S. N. et al. Plant membrane assays with cytokinin receptors underpin the unique role of free cytokinin bases as biologically active ligands. J. Exp. Bot. 66, 1851-1863 (2015).

9. Kamínek, M., Motyka, V. \& Vaňková, R. Regulation of cytokinin content in plant cells. Physiol. Plant. 101, 689-700 (1997).

10. Gu, J. et al. Roles of nitrogen and cytokinin signals in root and shoot communications in maximizing of plant productivity and their agronomic applications. Plant Sci. 274, 320-331 (2018).

11. Romanov, G. A., Lomin, S. N. \& Schmülling, T. Cytokinin signaling: from the ER or from the PM? That is the question! New Phytol. 218, 41-53 (2018).

12. Veach, Y. K. et al. O-glucosylation of cis-zeatin in maize. Characterization of genes, enzymes, and endogenous cytokinins. Plant Physiol. 131, 1374-1380 (2003).

13. Strnad, M. The aromatic cytokinins. Physiol. Plant. 101, 674-688 (1997).

14. Tarkowská, D. et al. Identification of new aromatic cytokinins in Arabidopsis thaliana and Populus $x$ canadensis leaves by LC-(+) ESI-MS and capillary liquid chromatography/frit-fast atom bombardment mass spectrometry. Physiol. Plant. 117, 579-590 (2003).

15. Žižková, E. et al. Control of cytokinin and auxin homeostasis in cyanobacteria and algae. Ann. Bot. Lond. 119, 151-166 (2017).

16. Záveská Drábková, L., Dobrev, P. I. \& Motyka, V. Phytohormone profiling across the Bryophytes. PloS ONE 10, e0125411, https:// doi.org/10.1371/journal.pone.0125411 (2015).

17. Gajdošová, S. et al. Distribution, biological activities, metabolism and the conceivable function of cis-zeatin-type cytokinins in plants. J. Exp. Bot. 62, 2827-2840 (2011).

18. Romanov, G. A. et al. Effect of indole-3-acetic acid and kinetin on tuberisation parameters of different cultivars and transgenic lines of potato in vitro. Plant Growth Regul. 32, 245-251 (2000).

19. Sarkar, D., Pandey, S. K. \& Sharma, S. Cytokinins antagonize the jasmonates action on the regulation of potato (Solanum tuberosum) tuber formation in vitro. Plant Cell Tiss. Organ Cult. 87, 285-295 (2006).

20. Malkawi, A., Jensen, B. L. \& Langille, A. R. Plant hormones isolated from "Katahdin" potato plant tissues and the influence of photoperiod and temperature on their levels in relation to tuber induction. J. Plant Growth Regul. 26, 308-317 (2007).

21. Hartmann, A., Senning, M., Hedden, P., Sonnewald, U. \& Sonnewald, S. Reactivation of meristem activity and sprout growth of potato tubers require both cytokinin and gibberellin. Plant Physiol. 155, 776-796 (2011).

22. Raspor, M. et al. Cytokinin profiles of AtCKX2-overexpressing potato plants and the impact of altered cytokinin homeostasis on tuberization in vitro. J. Plant Growth Regul. 31, 460-470 (2012).

23. Raspor, M. et al. Overexpressing AtCKX1 in potato plants grown in vitro: The effects on cytokinin composition and tuberization. J. Plant Growth Regul., https://doi.org/10.1007/s00344-020-10080-w(2020).

24. Schmülling, T., Fladung, M., Grossmann, K. \& Schell, J. Hormonal content and sensitivity of transgenic tobacco and potato plants expressing single rol genes of Agrobacterium rhizogenes T-DNA. Plant J. 3, 371-382 (1993).

25. Dermastia, M., Ravnikar, M. \& Kovač, M. Morphology of potato (Solanum tuberosum L. cv. Sante) stem node cultures in relation to the level of endogenous cytokinins. J. Plant Growth Regul. 15, 105-108 (1996).

26. Yakovleva, L. A., Cheredova, E. P. \& Karavaiko, N. N. Cytokinins and cytokinin-binding sites in transgenic potato plants. Plant Growth Regul. 21, 71-73 (1997).

27. Macháčková, I. et al. Growth pattern, tuber formation and hormonal balance in in vitro potato plants carrying ipt gene. Plant Growth Regul. 21, 27-36 (1997).

28. Macháčková, I. et al. Photoperiodic control of growth, development and phytohormone balance in Solanum tuberosum. Physiol. Plant. 102, 272-278 (1998).

29. De Jong, H. et al. Development and characterization of an adapted form of Droopy, a diploid potato mutant deficient in abscisic acid. Amer. J. Potato Res. 78, 279-290 (2001).

30. Muñiz García, M. N., Stritzler, M. \& Capiati, D. A. Heterologous expression of Arabidopsis ABF4 gene in potato enhances tuberization through ABA-GA crosstalk regulation. Planta 239, 615-631 (2014).

31. Kolachevskaya, O. O. et al. Expression of auxin synthesis gene tms1 under control of tuber-specific promoter enhances potato tuberization in vitro. J. Integr. Plant Biol. 57, 734-744 (2015).

32. Kolachevskaya, O. O. et al. Auxin synthesis gene tms 1 driven by tuber-specific promoter alters hormonal status of transgenic potato plants and their responses to exogenous phytohormones. Plant Cell Rep. 36, 419-435 (2017).

33. Kolachevskaya, O. O. et al. Core features of the hormonal status in in vitro grown potato plants. Plant Signal. Behav. 13, e1467697, https://doi.org/10.1080/15592324.2018.1467697 (2018).

34. Baroja-Fernández, E., Aguirreolea, J., Martínková, H., Hanuš, J. \& Strnad, M. Aromatic cytokinins in micropropagated potato plants. Plant Physiol. Biochem. 40, 217-224 (2002).

35. Barrs, H. D. Determination of water deficit in plant tissues in Water deficits and plant growth (ed. Kozlowski, T. T.) 235-368 (CSIRO Publishing, 1968).

36. Ciura, J. \& Kruk, J. Phytohormones as targets for improving plant productivity and stress tolerance. J. Plant Physiol. 229, 32-40 (2018).

37. Potato Genome Sequencing Consortium. Genome sequence and analysis of the tuber crop potato. Nature 475, 189-195 (2011).

38. Jackson, S. D. Multiple signaling pathways control tuber induction in potato. Plant Physiol. 119, 1-8 (1999).

39. Lomin, S. N. et al. Cytokinin perception in potato: new features of canonical players. J. Exp. Bot. 69, 3839-3853 (2018).

40. Ćosić, T. et al. In vitro shoot organogenesis and comparative analysis of endogenous phytohormones in kohlrabi (Brassica oleracea var. gongylodes): effects of genotype, explant type and applied cytokinins. Plant Cell Tiss. Organ Cult. 121, 741-760 (2015).

41. Trifunović-Momčilov, M. et al. Endogenous phytohormones in spontaneously regenerated Centaurium erythraea Rafn. plants grown in vitro. J. Plant Growth Regul. 35, 543-552 (2016).

42. Letham, D. S. Cytokinins as phytohormones - sites of biosynthesis, translocation, and function of translocated cytokinin in Cytokinins: Chemistry, activity and function (eds. Mok, D. W. S. \& Mok, M. C.) 57-80 (CRC Press, 1994).

43. Corbesier, L. et al. Cytokinin levels in leaves, leaf exudate and shoot apical meristem of Arabidopsis thaliana during floral transition. J. Exp. Bot. 54, 2511-2517 (2003).

44. Takei, K., Sakakibara, H., Taniguchi, M. \& Sugiyama, T. Nitrogen-dependent accumulation of cytokinins in root and the translocation to leaf: Implication of cytokinin species that induces gene expression of Maize Response Regulator. Plant Cell Physiol. 42, 85-93 (2001). 
45. Takei, K., Yamaya, T. \& Sakakibara, H. Arabidopsis CYP735A1 and CYP735A2 encode cytokinin hydroxylases that catalyze the biosynthesis of trans-zeatin. J. Biol. Chem. 279, 41866-41872 (2004).

46. Kiba, T., Takei, K., Kojima, M. \& Sakakibara, H. Side-chain modification of cytokinins controls shoot growth in Arabidopsis. Dev. Cell 27, 452-461 (2013).

47. Noodén, L. D. \& Letham, D. S. Cytokinin metabolism and signalling in the soybean plant. Aust. J. Plant Physiol. 20, 639-653 (1993).

48. Osugi, A. et al. Systemic transport of trans-zeatin and its precursor have differing roles in Arabidopsis shoots. Nat. Plants 3, 17112, https://doi.org/10.1038/nplants.2017.112 (2017).

49. Ko, D. et al. Arabidopsis ABCG14 is essential for the root-to-shoot translocation of cytokinin. Proc. Natl. Acad. Sci. USA 111, 7150-7155 (2014).

50. Zhang, K. et al. Arabidopsis ABCG14 protein controls the acropetal translocation of root-synthesized cytokinins. Nat. Commun. 5, 3274, https://doi.org/10.1038/ncomms4274 (2014)

51. Mok, M. C. et al. Topolins and hydroxylated thidiazuron derivatives are substrates of cytokinin $O$-glucosyltransferase with position specificity related to receptor recognition. Plant Physiol. 137, 1057-1066 (2005).

52. Eklöf, S. et al. Auxin-cytokinin interactions in wild-type and transgenic tobacco. Plant Cell Physiol. 38, 225-235 (1997).

53. Nordström, A. et al. Auxin regulation of cytokinin biosynthesis in Arabidopsis thaliana: A factor of potential importance for auxincytokinin-regulated development. Proc. Natl. Acad. Sci. USA 101, 8039-8044 (2004).

54. Jones, B. et al. Cytokinin regulation of auxin synthesis in Arabidopsis involves a homeostatic feedback loop regulated via auxin and cytokinin signal transduction. Plant Cell 22, 2956-2969 (2010).

55. Liu, J., Mehdi, S., Topping, J., Tarkowski, P. \& Lindsey, K. Modelling and experimental analysis of hormonal crosstalk in Arabidopsis. Mol. Syst. Biol. 6, 373, https://doi.org/10.1038/msb.2010.26 (2010).

56. Skoog, F. \& Miller, C. O. Chemical regulation of growth and organ formation in plant tissues cultured in vitro. Symp. Soc. Exp. Biol. 11, 118-130 (1957)

57. Pal, A. K., Acharya, K. \& Ahuja, P. S. Endogenous auxin level is a critical determinant for in vitro adventitious shoot regeneration in potato (Solanum tuberosum L.). J. Plant Biochem. Biotechnol. 21, 205-212 (2012).

58. López-Carbonell, M. \& Jáuregui, O. A rapid method for analysis of abscisic acid (ABA) in crude extracts of water stressed Arabidopsis thaliana plants by liquid chromatography-mass spectrometry in tandem mode. Plant Physiol. Biochem. 43, 407-411 (2005).

59. Cutler, A. J. \& Krochko, J. E. Formation and breakdown of ABA. Trends Plant Sci. 4, 472-478 (1999).

60. Kushiro, T. et al. The Arabidopsis cytochrome P450 CYP707A encodes ABA 8'-hydroxylases: key enzymes in ABA catabolism. ЕМBO J. 23, 1647-1656 (2004).

61. Vinterhalter, D. et al. Diurnal rhythmicity of endogenous phytohormones and phototropic bending capacity in potato (Solanum tuberosum L.) shoot cultures. Plant Growth Regul. 90, 151-161 (2020).

62. Xiong, L. \& Zhu, J. K. Regulation of abscisic acid biosynthesis. Plant Physiol. 133, 29-36 (2003).

63. Tuteja, N. Abscisic acid and abiotic stress signaling. Plant Signal. Behav. 2, 135-138 (2007).

64. Seabrook, J. E. A. Light effects on the growth and morphogenesis of potato (Solanum tuberosum). in vitro: A review. Amer. J. Potato Res. 82, 353-367 (2005).

65. Tanaka, K., Fujiwara, K. \& Kozai, T. Effects of relative humidity in the culture vessel on the transpiration and net photosynthetic rates of potato plantlets in vitro. Acta Hortic. 319, 59-64 (1992).

66. Buddendorf-Joosten, J. M. C. \& Woltering, E. J. Controlling the gaseous composition in vitro - description of a flow system and effects of the different gaseous components on in vitro growth of potato plantlets. Sci. Hortic-Amsterdam 65, 11-23 (1996).

67. Wolf, S., Kalman-Rotem, N., Yakir, D. \& Ziv, M. Autotrophic and heterotrophic carbon assimilation of in vitro grown potato (Solanum tuberosum L.) plants. J. Plant Physiol. 153, 574-580 (1998).

68. Dragićević, I., Konjević, R., Vinterhalter, B., Vinterhalter, D. \& Nešković, M. The effects of IAA and tetcyclacis on tuberization in potato (Solanum tuberosum L.) shoot cultures in vitro. Plant Growth Regul. 54, 189-193 (2008).

69. Murashige, T. \& Skoog, F. A revised medium for rapid growth and bio assays with tobacco tissue cultures. Physiol. Plant. 15, 473-497 (1962).

70. Linsmaier, E. M. \& Skoog, F. Organic growth factor requirements of tobacco tissue cultures. Physiol. Plant. 18, 100-127 (1965).

71. Dobrev, P. I. \& Kamínek, M. Fast and efficient separation of cytokinins from auxin and abscisic acid and their purification using mixed-mode solid-phase extraction. J. Chromatogr. A 950, 21-29 (2002).

72. Dobrev, P. I., Havlíček, L., Vágner, M., Malbeck, J. \& Kamínek, M. Purification and determination of plant hormones auxin and abscisic acid using solid phase extraction and two-dimensional high performance liquid chromatography. J. Chromatogr. A 1075, 159-166 (2005).

\section{Acknowledgements}

The authors are grateful to Marie Korecká for invaluable technical support. This work was supported by the Ministry of Education, Science and Technological Development of Serbia (Research Grant No. OI173015), the Czech Science Foundation (Grants No. 19-12262S and 19-13103S) and the Ministry of Education, Youth and Sports of Czech Republic from European Regional Development Fund-Project "Centre for Experimental Plant Biology" (No. CZ.02.1.01/0.0/0.0/16_019/0000738).

\section{Author contributions}

M.R., V.M., S.N. and I.Č.D. designed the research and wrote the manuscript. P.I.D. and J.M. performed the phytohormone measurements, and M.R., V.M., T.C. and V.T. analysed the results of the measurements. A.C. and J.S. compiled and reviewed the literature data on hormonal measurements in potato. All authors reviewed the manuscript.

\section{Competing interests}

The authors declare no competing interests.

\section{Additional information}

Supplementary information is available for this paper at https://doi.org/10.1038/s41598-020-60412-9.

Correspondence and requests for materials should be addressed to M.R.

Reprints and permissions information is available at www.nature.com/reprints.

Publisher's note Springer Nature remains neutral with regard to jurisdictional claims in published maps and institutional affiliations. 
(c) (i) Open Access This article is licensed under a Creative Commons Attribution 4.0 International License, which permits use, sharing, adaptation, distribution and reproduction in any medium or format, as long as you give appropriate credit to the original author(s) and the source, provide a link to the Creative Commons license, and indicate if changes were made. The images or other third party material in this article are included in the article's Creative Commons license, unless indicated otherwise in a credit line to the material. If material is not included in the article's Creative Commons license and your intended use is not permitted by statutory regulation or exceeds the permitted use, you will need to obtain permission directly from the copyright holder. To view a copy of this license, visit http://creativecommons.org/licenses/by/4.0/.

(C) The Author(s) 2020 